\title{
Three-dimensional printing in cardiology: Current applications and future challenges
}

\author{
Hongxing Luo ${ }^{1 *}$, Jarosław Meyer-Szary ${ }^{2 *}$, Zhongmin Wang ${ }^{1}$, \\ Robert Sabiniewicz ${ }^{2 *}$, Yuhao $\mathrm{Liu}^{1 *}$ \\ ${ }^{1}$ Department of Cardiology, Zhengzhou University People's Hospital \\ (Henan Provincial People's Hospital), Zhengzhou, Henan, China \\ ${ }^{2}$ Department of Pediatric Cardiology and Congenital Heart Diseases, \\ Medical University of Gdansk, Poland
}

\begin{abstract}
Three-dimensional (3D) printing has attracted a huge interest in recent years. Broadly speaking, it refers to the technology which converts a predesigned virtual model to a touchable object. In clinical medicine, it usually converts a series of two-dimensional medical images acquired through computed tomography, magnetic resonance imaging or $3 D$ echocardiography into a physical model. Medical $3 D$ printing consists of three main steps: image acquisition, virtual reconstruction and $3 D$ manufacturing. It is a promising tool for preoperative evaluation, medical device design, hemodynamic simulation and medical education, it is also likely to reduce operative risk and increase operative success. However, the most relevant studies are case reports or series which are underpowered in testing its actual effect on patient outcomes. The decision of making a $3 D$ cardiac model may seem arbitrary since it is mostly based on a cardiologist's perceived difficulty in performing an interventional procedure. A uniform consensus is urgently necessary to standardize the key steps of $3 D$ printing from imaging acquisition to final production. In the future, more clinical trials of rigorous design are possible to further validate the effect of 3D printing on the treatment of cardiovascular diseases. (Cardiol J 2017; 24, 4: 436-444)

Key words: three-dimensional printing, cardiology, preoperative evaluation, device design, medical education
\end{abstract}

\section{Introduction}

Three-dimensional (3D) printing (rapid prototyping, additive manufacturing) is a technology which manufactures a $3 \mathrm{D}$ object with a predesigned, computerized model commonly in a layerby-layer manner [1]. Medical 3D printing consists mainly of the following steps: image acquisition, virtual reconstruction and 3D manufacturing [2]. In most cases, virtual models are reconstructed from a series of medical images acquired through computed tomography (CT), magnetic resonance imaging (MRI) or 3D echocardiography. 3D print- ing has been greatly developed in recent years by clinicians as a visualized aid for preoperative planning of orthopedic surgery, plastic surgery, and oncological surgery among other procedures [3]. Some clinicians have also used it for intraoperative orientation, postoperative follow-up, device design, hemodynamic simulation and medical education [4-7]. Up until recently it was unsure whether this new technique is merely a gizmo and would fade into the past as yet more scientific hype (as some sceptics have claimed) or whether it would actually prove to be clinically usefull. The developments in the most recent years indicate it might be

Address for correspondence: Dr. Hongxing Luo, Department of Cardiology, Zhengzhou University People's Hospital, Zhengzhou, Henan, China, 450003, tel: +86 15290885448, e-mail: 1519782837@qq.com

*Share authorship 


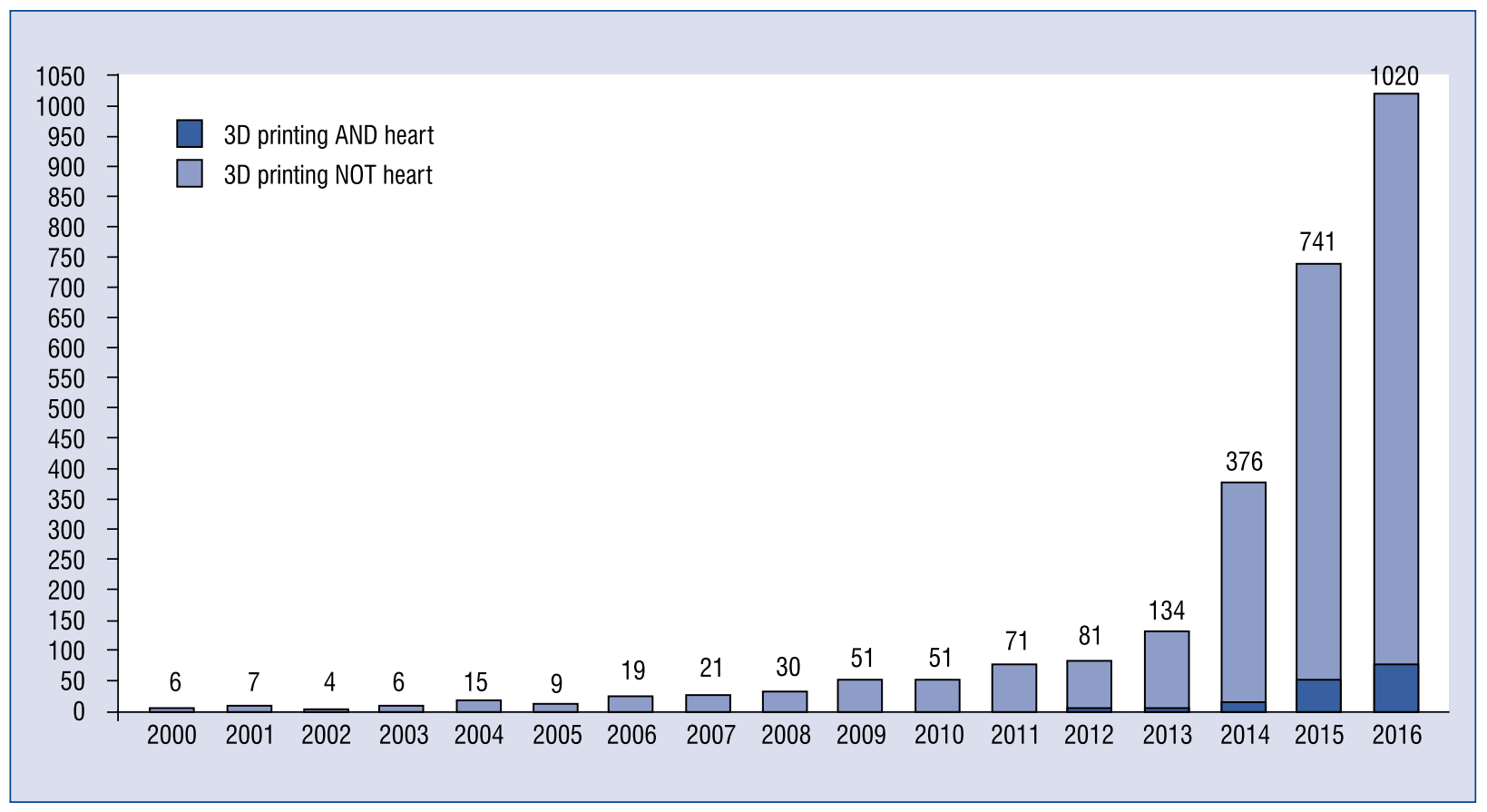

Figure 1. PubMed trends showing an increasing number of indexed publications on three-dimensional (3D) printing AND/NOT heart (any field).

worthwhile to further pursue the path. At this point is seems to be a true hope for future advances in medicine. The exponential growth in the number of publications in the field as pictured by the PubMed trend (Fig. 1) confirms an increasing interest in 3D printing by the scientific community.

Here we systematically review the current applications of 3D printing with regard to cardiovascular diseases (CVD), and highlight several challenges to be addressed in the future, based on a systematic search of the Medline database via PubMed on September 30, 2016 using search strategies listed in Supplement 1 (see journal website, supplementary file). All retrieved abstracts were first screened to exclude cell/animal studies and duplication publications, and full articles were further downloaded and examined to include studies on the utilities of 3D printing in CVD. Primarily a total of 322 articles were searched, and a total of 59 articles were finally included in this review.

\section{Current applications of $3 \mathrm{D}$ printing to $\mathrm{CVD}$}

Table 1 summarizes the applications of 3D printing to operative evaluation, device design and hemodynamic simulation of CVD, based on the studies of more than 4 cases. Table 2 is a summary of studies reporting fewer cases.

\section{Preoperative, intraoperative} and postoperative evaluations

In 2006, Ngan et al. [8] generated 3D printing models for the preoperative planning of 6 patients with pulmonary atresia, ventricular septal defect (VSD) and major aortopulmonary collateral arteries. They found that 3D models accurately showed $96 \%$ of major aortopulmonary collateral arteries when compared with findings during surgery. However, their 3D printing models were rigid and thus unable to represent the flexibility and motility of a real human heart. Soon Noecker et al. [9] created several cardiac models using polyurethane materials. Their cardiac models could be compressed using the fingers, representing the first attempt at making a flexible model. However, both studies employed CT which is invasive for patients when acquiring raw data for 3D printing. In 2007, Schievano et al. [10] and Armillotta et al. [11] used MRI datasets to print several right ventricular outflow tract models for preoperative guidance of percutaneous pulmonary valve implantation. 3D echocardiography was first used for 3D printing in 2014. Mahmood et al. [12] produced mitral valve annuli with 3D transesophageal echocardiography 
Table 1. Summary of the applications of three dimensional printing to cardiovascular diseases based on the studies of $\geq 5$ cases.

\begin{tabular}{|c|c|c|c|c|}
\hline Categories & References & $\begin{array}{l}\text { Sample } \\
\text { size }\end{array}$ & $\begin{array}{l}\text { Imaging } \\
\text { techniques }\end{array}$ & Diseases \\
\hline \multirow{11}{*}{$\begin{array}{l}\text { Preoperative } \\
\text { evaluation }\end{array}$} & Ngan EM, 2006 [8] & 6 & CT & Pulmonary atresia, VSD, MAPCA \\
\hline & Noecker AM, 2006 [9] & 11 & CT & $\begin{array}{l}\text { Double arch with bilateral type B inter- } \\
\text { ruption, RAA, aberrant LSCA, Kommerell's } \\
\text { diverticulum, TOF, anomalous RCA from } \\
\text { LCA, anomalous LCA from RCA, peripheral } \\
\text { pulmonic stenosis, aortic coarctation, } \\
\text { normal cases }\end{array}$ \\
\hline & Schievano S, $2007[10,11]$ & 12 & MRI & $\begin{array}{l}\text { TOF, homograft conduit, homograft } \\
\text { monocusp patch, transannular patch }\end{array}$ \\
\hline & Mahmood F, 2014 [12] & 5 & 3D TEE & Ischemic MR, myxomatous valve disease \\
\hline & Koleilat I, 2015 [38] & 7 & CT & $\begin{array}{l}\text { Juxtarenal, pararenal, or suprarenal } \\
\text { abdominal aortic aneurysm }\end{array}$ \\
\hline & Schmauss D, 2015 [37] & 8 & $\mathrm{CT}, \mathrm{MRI}$ & $\begin{array}{l}\text { Left retro-oesophageal abnormal } \\
\text { subclavian artery and right descending } \\
\text { aorta, subpulmonary VSD, hypoplastic } \\
\text { left heart syndrome, pulmonary atresia, } \\
\text { hypoplastic right ventricle, AS, primary } \\
\text { right ventricular tumor, frontolateral } \\
\text { pseudoaneurysm, severe AVS }\end{array}$ \\
\hline & Anwar S, 2016 [28] & 9 & $\mathrm{CT}, \mathrm{MRI}$ & $\begin{array}{c}\text { Circumflex distal arch, TOF + pulmonary } \\
\text { atresia + major aortopulmonary collaterals, } \\
\text { anomalous pulmonary venous return, } \\
\text { dextrocardia + DORV + I-TGA, ASD + } \\
\text { DORV + VSD + d-TGA + severe valvar PS, } \\
\text { superoinferior ventricles + ASD + VSD, } \\
\text { heterotaxy syndrome + single ventricle }\end{array}$ \\
\hline & Liu P, 2016 [13] & 8 & 3D TEE & Persistent atrial fibrillation \\
\hline & Garekar S, 2016 [39] & 6 & CT, MRI & DORV, VSD \\
\hline & Ripley B, 2016 [40] & 16 & CT & Paravalvular aortic regurgitation \\
\hline & Ma XJ, 2015 [4] & 35 & MSCT & TOF \\
\hline \multirow{3}{*}{$\begin{array}{l}\text { Device } \\
\text { design }\end{array}$} & Park CY, 1997 [15] & 9 & MRI & Cardiomyopathy \\
\hline & Pepper J, 2013 [6] & 34 & $\begin{array}{l}\text { MRI or CT } \\
\quad+\text { CAD }\end{array}$ & Marfan aortic root \\
\hline & Kurenov SN, 2015 [18] & 10 & CT & Pulmonary artery \\
\hline $\begin{array}{l}\text { Hemodynamic } \\
\text { simulation }\end{array}$ & Maragiannis D, 2015 [7] & 8 & $\mathrm{CT}, \mathrm{CAD}$ & Severe AVS \\
\hline
\end{tabular}

AS — aortic stenosis; ASD — atrial septal defect; AVS — aortic valve stenosis; MR - mitral regurgitation; MRI - magnetic resonance imaging; 3D TEE — three-dimensional transesophageal echocardiography; CT — computed tomography; MSCT — multi-slice computed tomography; CAD — computer-aided design; d-TGA — d-transposition of the great arteries; I-TGA — I-transposition of the great arteries; DORV — double outlet right ventricle; PS - pulmonary stenosis, MAPCA - major aortopulmonary collateral arteries; RAA - right aortic arch; LSCA - left subclavian artery; RCA — right coronary artery; LCA — left coronary artery; VSD — ventricular septal defect; MV - mitral valve; TOF - tetralogy of Fallot

(TEE) datasets. Their study is a landmark for 3D printing of CVD because 3D TEE is much more frequently used in routine clinical practice when compared with CT and MRI. 3D-prined left atrial appendage models generated from 3D TEE have been recently used to optimize occluder selection preoperatively $[13,14]$. Last year, Ma et al. [4] reported the largest study of 3D-printed cardiac models for VSD repair in 35 cases with tetralogy of Fallot. Like Ngan et al. [8], they observed that the defect sizes were consistent between preoperative models and intraoperative measurements. 3D-printed cardiac model has also been applied to the postoperative evaluation of an atrial septal defect case in uncovering potential complications [5]. 
Table 2. Summary of applications of three-dimensional printing for cardiovascular diseases based on the studies of $\leq 4$ cases.

\begin{tabular}{ll}
\hline Imaging techniques & Diseases \\
\hline 3D TTE/TEE & Left atrial appendage occlusion [14], postoperative hemodynamic testing following \\
& MitraClip procedure [41] \\
MRI & TGA, VSD, PS [42], DORV [43], hypoplastic aortic arch [44], aortic arch aneurysm [45], \\
& pulmonary atresia, ASD, tricuspid regurgitation, dextrocardia [46], retroesophageal \\
& LSA + right aortic arch [47] \\
MSCT & ASD [48, 49], VSD [50], LAA occlusion [51], severe AS [52], extensive AA [53], severe \\
& mitral valve regurgitation [54], neopulmonary stenosis [55], primary dilated cardiomy- \\
& opathy [56], primary cardiac schwannoma [57], double-chambered right ventricle [58], \\
& severe pulmonary venous stenosis [59], complex aortic obstruction [60], juxtarenal AA \\
& [61], DOLV, VSD, PS [62], left atrium osteosarcoma [63], hypertrophic cardiomyopathy \\
& [64], prosthetic MV perivalvular leak [65], ventricular aneurysm [66], pulmonary venous \\
& baffle to the systemic right ventricle [67], tricuspid atresia [67], His bundle pacing [68] \\
\hline
\end{tabular}

AA - atherosclerotic aneurysm; rest abbreviations are the same with the Table 1

\section{Device development}

Although 3D printing is mostly used for preoperative evaluation at present, the first study of $3 \mathrm{D}$ printing of CVD is about medical device development [15]. In 1997, Park et al. [15] designed and printed ventricular chambers for totally implantable artificial hearts. Their seminal study demonstrated for the first time the potential of 3D printing in designing patient-specific medical devices. Nowadays, a medical device has to be tested by numerous animal experiments and various phases of clinical trials before it is finally applied to clinical practice [16]. 3D printing is likely to give us a new chance to simplify the current workflow of device development by allowing patient-specific device design. Schievano et al. [17] employed a 3Dprinted pulmonary trunk model to design a novel implantable pulmonary valve. Thirty-four external supports of Marfan aortic root were also designed and printed [6]. Pulmonary artery catheters were designed for regional lung chemotherapy [18]. Last year, the Food and Drug Administration (FDA) of the United States released the first regulation on $3 \mathrm{D}$ printing medical devices, in which $3 \mathrm{D}$ printing devices are categorized as Class II because it generally does not raise any new safety issues or effectiveness issues [19].

\section{Hemodynamic simulation}

Patients with valvular heart diseases have impaired hemodynamics, but it is unfeasible to isolate the effects of valve geometry on valvular function [20]. 3D-printed heart valves allow in vitro hemodynamic simulation [20]. Maragiannis et al. [7] used 8 severe aortic valve stenosis models to replicate the unique functional characteristics of the patients. Their models were likely to aid in the refined quantification of aortic root flow and aortic stenosis severity. These studies of hemodynamic simulation exemplify a new solution to mimic the in-vivo characteristics of the human body in an in-vitro manner.

\section{Medical education}

Complex structural heart diseases may not be easily comprehended by inexperienced cardiologists and medical students when only two-dimensional pictures are provided. 3D-printed cardiac models generated from the medical images of real patients are likely to reduce misinterpretations of pathological structures. Costello et al. [21, 22] printed various VSD models to teach 52 medical students and found a significant improvement in structural conceptualization. 3D-printed cardiac models improve the spatial orientation of medical students [23]. However, nurses appear to benefit more from model-guided education when compared with medical students [24]. As the difficulties of obtaining cadavers markedly increase in recent years, 3D printing may play an important role in anatomical education. Apart from the fact that it does not bring about ethical issues [25]. Lim et al. [26] it was also found that 3D-printed cardiac models are as effective as cadaveric materials for medical education.

\section{Several challenges to be addressed in the future}

Although 3D printing is likely to serve as a useful tool for clinical practice and medical education, some doubts have been raised [27]. Here 
three challenges are discussed which need to be addressed in the future.

How do we define the indications for $3 \mathrm{D}$ printing of cardiovascular models?

This question is inevitably the first to be answered by a cardiologist who wants to manufacture a cardiac model, but currently no guidelines are available for reference. Consequently, the decision of printing a cardiovascular model is based on its structural complexity. Unfortunately, scientific standards have not been developed to quantify the complexity of cardiovascular structures. It is not uncommon to see that when one cardiologist manufactures a 3D model of pulmonary stenosis [11], another cardiologist manufactures a 3D model of pulmonary stenosis, atrial septal defect, double outlet right ventricle, ventricular septal defect and d-transposition of the great arteries [28]. Many studies are case reports of rare diseases without control groups. They are underpowered in drawing from a robust conclusion on the efficacy of 3D printing for CVD. The indications for 3D printing may be resolved in the future by developing an expert consensus or guideline.

\section{Still an experiment}

One must bear in mind that $3 \mathrm{D}$ printing in medicine can be only applied purely on scientific grounds with all its limitations and restraints. Lacking is large scale evidence proving its clinical feasibility and safety. Thus, apart from ethical board approval, it must be considered whether the patient himself should consent on taking part in a medical experiment featuring printing of a model and its further use for decision making, even if no additional imaging is done (using already available imagery). It is concievable that a poorly made model may result in easily mislead clinical decisions giving rise to medical errors, just as a good model may aid in processes which lead to better patient outcomes.

Also, the legal status of models are unresolved. Is a basic model used to study a specific patient's anatomy just another form of medical documentation representing a new way to display medical imigary? Is a treatment simulation model a medical device or still a medical documentation? These and other similar ethical and legal issues remain to be resolved.

\section{Can a static cardiac model represent a real dynamic heart? \\ Image acquisition is the first step of medical 3D printing, but it generally captures a specific moment}

of cardiac cycle either at systole or diastole. Thus, 3D printing is incapable of reproducing the flexibility and mobility of a human heart. In 2007, Markert et al. [29] printed a cardiac model inflated with air. Their proofof-concept study is an inspiring step to manufacture a dynamic heart. Nevertheless, thereafter no similar studies have been conducted.

Moreover, the lack of a standard protocol for image acquisition and postprocessing undermines the quality of 3D-printed models. Motion artifacts introduced during image acquisition affects the subsequent extraction of region of interest [30]. It is challenging to separate cardiac tissues from the adjacent tissues of similar Hounsfield units. Image postprocessing greatly relies on the anatomical knowledge of clinical experts. Without image postprocessing, the quality of a 3D-printed model is poor [31]. A new method called blood pool segmentation has been recently proposed to more accurately extract the region of interest for $3 \mathrm{D}$ printing [32]. Integration of multiple imaging modalities may be a good solution in acquiring high-quality medical images. A combination of multi-slice CT (MSCT) and 3D TEE produces a more ideal model compared with MSCT alone [33, 34]. Fujita et al. [35] developed a preoperative algorithm encompassing chest X-ray, echocardiography and $3 \mathrm{D}$ printing for the preoperative evaluation of congenital heart diseases. Although the algorithm minimizes potential misunderstandings of cardiac anomalies, it also brings unnecessary imaging examinations and additional costs. In addition, the more we postprocess medical images, the more we may stray from the real anatomical structures. A balance between two-dimensional images and 3D models should be carefully achieved by those who want to use a printed a model.

\section{How can we make a cost-effective analysis before printing a model?}

Currently, in routine clinical practice, transthoracic echocardiography/transesophageal echocardiography, CT and MRI are sufficient to perform most procedures, even in challenging cases [36]. $3 \mathrm{D}$ printing is more cost-effective for challenging cases rather than routine cases. The cost and time of manufacturing a 3D model vary between $\$ 100-450$ and 30 min-107 h, respectively, depending on the size and materials of the model [12, $18,37]$. To print a 3D model, a cardiologist has to buy at least a $3 \mathrm{D}$ printer and the raw materials. Specialised, proprietary software streamlines the image postprocessing and segmentation further 


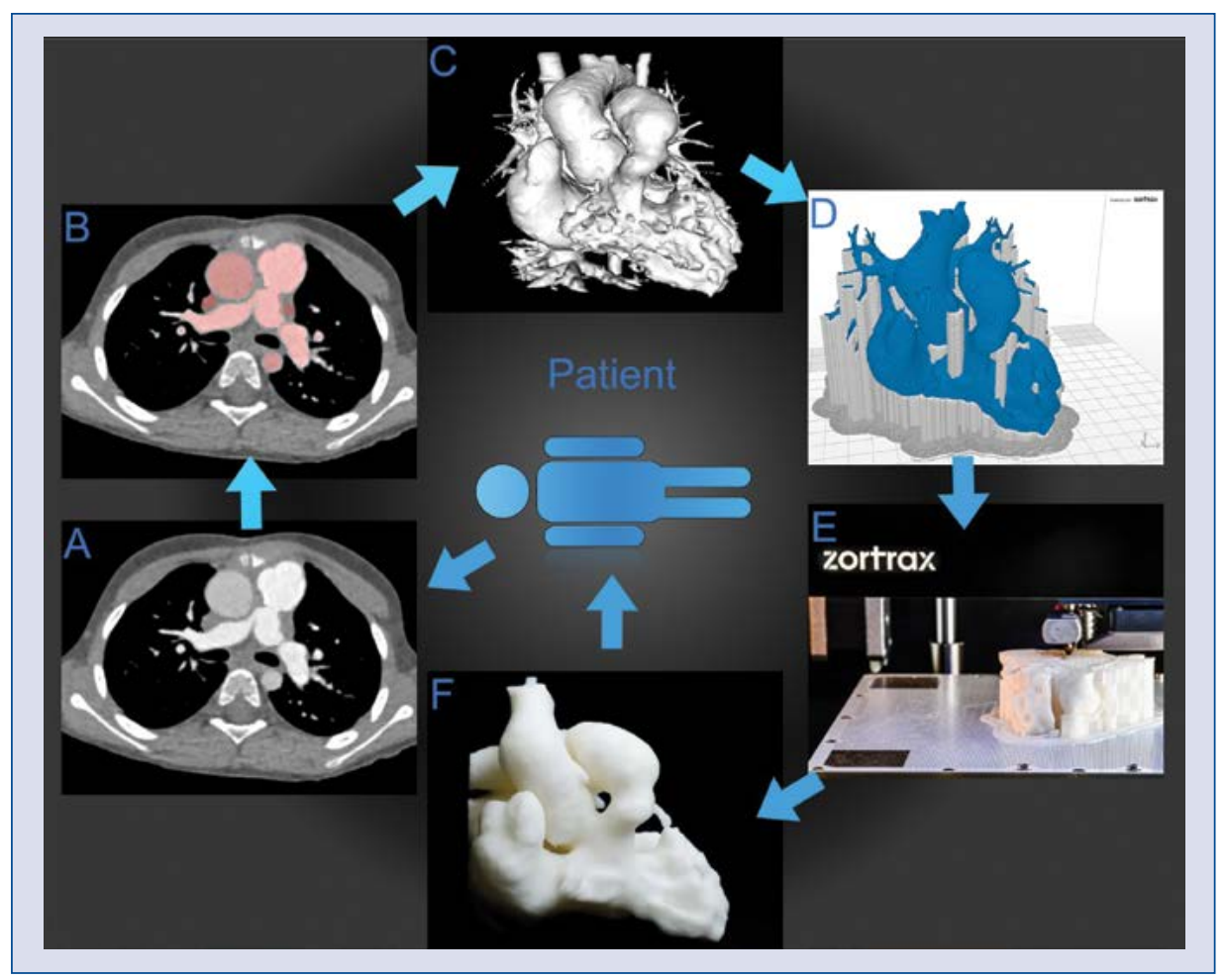

Figure 2. Summary of the three-dimensional (3D) printing process. One should notice that the patient and his clinical problem should be at the center of attention at every step. A. Imaging data aqusition; B. Image segmentation; C. Surface rendering, virtual model inspection, smoothing and retouching; D. Printing preparation and planning gray represents the supportive material; $\mathbf{E}$. Model additive manufacturing (3D printing) using fused deposition modelling technique; F. Final model after removing supportive material.

increasing the upfront expenses. Another way of manufacturing a 3D model is outsourcing the imaging postprocessing and 3D manufacturing tasks to an industrial company [2]. Either way, not all patients can afford this at present. 3D printing is also time-consuming. Virtual reconstruction generally comprises multiple steps including thresholding, region growing, mask calculation, model smoothing, and so on (Fig. 2). During the final manufacturing process, a model is commonly printed in a layer-by-layer manner with the thickness of usually 0.1-1 mm (Video Appendix 1 - see journal website, supplementary file). Although CT is currently the most common imaging modality for 3D printing, it brings radiation exposure and additional medical expenditure to the patient. Therefore, many factors may affect the clinical decision to make a 3D model. Before printing a cardiac model, a cardiologist should consider a cost-effectiveness analysis to minimize the potential harm while maximizing the potential benefits of $3 \mathrm{D}$ printing for the patient.

\section{Future standard of care?}

If at any point in the future printing of medical $3 \mathrm{D}$ models is to become the standard of care (in selected cases) it will not only need to become simpler and less time consuming but most importantly it will not only need to gather enough scientific evidence of clinical safety and usefulness to successfully undergo FDA (and its country specific counterpart) certification. It will also need to prove to be cost-efficient to be covered by the health insurance. Despite the fact that in the nearest future 3D-printed heart models are currently deemed to be confined to the walls of the university hospitals, as its best suited to aid in finding solutions to the most complex cases, one cannot expect widespread use without proper reimbursement of the procedure.

\section{Conclusions}

Nearly two decades have passed since the first report of 3D printing in cardiology. 3D printing has been developed for different purposes includ- 
ing preoperative evaluation, device development, hemodynamic simulation and medical education. The majority of studies are case reports which are insufficient in drawing a robust conclusion on the efficacy of 3D printing for CVD. More studies of rigorous design are needed to validate its effect on an ever changing clinical practice.

\section{Acknowledgements}

This work has been supported by the Henan Provincial Key Medical Program (Henan Provincial Department of Science and Technology) and the Henan Provincial New Medical Technology Program (Health and Family Planning Commission of Henan Province) as well as Medical University of Gdansk, Poalnd.

\section{Conflict of interest: None declared}

\section{References}

1. Matsumoto JS, Morris JM, Foley TA, et al. Three-dimensional Physical Modeling: Applications and Experience at Mayo Clinic. Radiographics. 2015; 35(7): 1989-2006, doi: 10.1148/ rg.2015140260, indexed in Pubmed: 26562234.

2. Giannopoulos AA, Mitsouras D, Yoo SJ, et al. Applications of 3D printing in cardiovascular diseases. Nat Rev Cardiol. 2016; 13(12): 701-718, doi:10.1038/nrcardio.2016.170, indexed in Pubmed: 27786234.

3. Martelli N, Serrano C, van den Brink H, et al. Advantages and disadvantages of 3-dimensional printing in surgery: A systematic review. Surgery. 2016; 159(6): 1485-1500, doi: 10.1016/j. surg.2015.12.017, indexed in Pubmed: 26832986.

4. Ma XJ, Tao L, Chen X, et al. Clinical application of three-dimensional reconstruction and rapid prototyping technology of multislice spiral computed tomography angiography for the repair of ventricular septal defect of tetralogy of Fallot. Genet Mol Res. 2015; 14(1): 1301-1309, doi:10.4238/2015.February.13.9, indexed in Pubmed: 25730069.

5. Wang Z, Luo H, Gao C, et al. Three-dimensional printing model for the postoperative follow-up of atrial septal defect. Int J Cardiol. 2016; 222: 891-892, doi: 10.1016/j.jijcard.2016.08.046, indexed in Pubmed: 27522396.

6. Pepper J, Petrou M, Rega F, et al. Implantation of an individually computer-designed and manufactured external support for the Marfan aortic root. Multimed Man Cardiothorac Surg. 2013; 2013: mmt004, doi: 10.1093/mmcts/mmt004, indexed in Pubmed: 24413003 .

7. Maragiannis D, Jackson MS, Igo SR, et al. Replicating patientspecific severe aortic valve stenosis with functional 3D modeling. Circ Cardiovasc Imaging. 2015; 8(10): e003626, doi: 10.1161/ CIRCIMAGING.115.003626, indexed in Pubmed: 26450122.

8. Ngan E, Rebeyka I, Ross D, et al. The rapid prototyping of anatomic models in pulmonary atresia. J Thorac Cardiovasc Surg. 2006; 132(2): 264-269, doi: 10.1016/j.jtcvs.2006.02.047.

9. Noecker AM, Chen JF, Zhou Q, et al. Development of patientspecific three-dimensional pediatric cardiac models. ASAIO J. 2006; 52(3): 349-353.
10. Schievano S, Migliavacca F, Coats L, et al. Percutaneous pulmonary valve implantation based on rapid prototyping of right ventricular outflow tract and pulmonary trunk from MR data. Radiology. 2007; 242(2): 490-497, doi: 10.1148/radiol.2422051994, indexed in Pubmed: 17255420.

11. Armillotta A, Bonhoeffer P, Dubini G, et al. Use of rapid prototyping models in the planning of percutaneous pulmonary valved stent implantation. Proc Inst Mech Eng H. 2007; 221(4): 407-416, doi: 10.1243/09544119JEIM83, indexed in Pubmed: 17605398.

12. Mahmood F, Owais K, Montealegre-Gallegos M, et al. Echocardiography derived three-dimensional printing of normal and abnormal mitral annuli. Ann Card Anaesth. 2014; 17(4): 279-283, doi: 10.4103/0971-9784.142062, indexed in Pubmed: 25281624.

13. Liu P, Liu R, Zhang Y, et al. The value of 3D printing models of left atrial appendage using real-time 3D transesophageal echocardiographic data in left atrial appendage occlusion: applications toward an era of truly personalized medicine. Cardiology. 2016; 135(4): 255-261, doi: 10.1159/000447444, indexed in Pubmed: 27537503.

14. Fan Y, Kwok KW, Zhang Y, et al. Three-dimensional printing for planning occlusion procedure for a double-lobed left atrial appendage. Circ Cardiovasc Interv. 2016; 9(3): e003561, doi: 10.1161/CIRCINTERVENTIONS.116.003561, indexed in Pubmed: 26945027.

15. Park CY, Chang JK, Jeong DY, et al. Development of a custom designed TAH using rapid prototyping. ASAIO J. 1997; 43(5): M647-M650, indexed in Pubmed: 9360125.

16. Holmes DR, Califf R, Farb A, et al. Overcoming the challenges of conducting early feasibility studies of medical devices in the United States. J Am Coll Cardiol. 2016; 68(17): 1908-1915, doi: 10.1016/j.jacc.2016.07.769, indexed in Pubmed: 27765194.

17. Schievano S, Taylor AM, Capelli C, et al. First-in-man implantation of a novel percutaneous valve: a new approach to medical device development. EuroIntervention. 2010; 5(6): 745-750, indexed in Pubmed: 20142228.

18. Kurenov S, Ionita C, Sammons D, et al. Three-dimensional printing to facilitate anatomic study, device development, simulation, and planning in thoracic surgery. J Thorac Cardiovasc Surg. 2015; 149(4): 973-979.e1, doi: 10.1016/j.jtcvs.2014.12.059.

19. Prima MDi, Coburn J, Hwang D, et al. Additively manufactured medical products - the FDA perspective. 3D Printing in Medicine. 2015; 2(1).

20. Herrmann TA, Siefert AW, Pressman GS, et al. In vitro comparison of Doppler and catheter-measured pressure gradients in 3D models of mitral valve calcification. J Biomech Eng. 2013; 135(9): 94502, doi: 10.1115/1.4024579, indexed in Pubmed: 23720100.

21. Costello JP, Olivieri LJ, Krieger A, et al. Utilizing three-dimensional printing technology to assess the feasibility of high-fidelity synthetic ventricular septal defect models for simulation in medical education. World J Pediatr Congenit Heart Surg. 2014; 5(3): 421-426, doi: 10.1177/2150135114528721, indexed in Pubmed: 24958045.

22. Costello JP, Olivieri LJ, Su L, et al. Incorporating three-dimensional printing into a simulation-based congenital heart disease and critical care training curriculum for resident physicians. Congenit Heart Dis. 2015; 10(2): 185-190, doi: 10.1111/chd.12238, indexed in Pubmed: 25385353.

23. Biglino G, Capelli C, Koniordou D, et al. Use of 3D models of congenital heart disease as an education tool for cardiac nurses. Con- 
genit Heart Dis. 2017; 12(1): 113-118, doi: 10.1111/chd.12414, indexed in Pubmed: 27666734.

24. Olivieri LJ, Su L, Hynes CF, et al. World J Pediatr Congenit Heart Surg. 2016; 7(2): 164-168, doi: 10.1177/2150135115623961, indexed in Pubmed:26957398.

25. Estai M, Bunt S. Best teaching practices in anatomy education: A critical review. Ann Anat. 2016; 208: 151-157, doi: 10.1016/j. aanat.2016.02.010, indexed in Pubmed: 26996541.

26. Lim KH, Loo ZY, Goldie SJ, et al. Use of 3D printed models in medical education: A randomized control trial comparing 3D prints versus cadaveric materials for learning external cardiac anatomy. Anat Sci Educ. 2016; 9(3): 213-221, doi: 10.1002/ ase.1573, indexed in Pubmed: 26468636.

27. Ryan J, Gregg C, Frakes D, et al. Three-dimensional printing: changing clinical care or just a passing fad? Curr Opin Cardiol. 2017; 32(1): 86-92, doi:10.1097/HCO.0000000000000352, indexed in Pubmed: 27861185.

28. Anwar S, Singh GK, Varughese J, et al. 3D printing in complex congenital heart disease: across a spectrum of age, pathology, and imaging techniques. JACC Cardiovasc Imaging. 2016 [Epub ahead of print], doi: 10.1016/j.jcmg.2016.03.013, indexed in Pubmed: 27450874.

29. Markert M, Weber S, Lueth TC. A beating heart model 3D printed from specific patient data. Conf Proc IEEE Eng Med Biol Soc. 2007; 2007: 4472-4475, doi: 10.1109/IEMBS.2007.4353332, indexed in Pubmed: 18002998.

30. Ogden KM, Aslan C, Ordway N, et al. Factors affecting dimensional accuracy of 3-D printed anatomical structures derived from CT data. J Digit Imaging. 2015; 28(6): 654-663, doi: 10.1007/ s10278-015-9803-7, indexed in Pubmed: 25982877.

31. Mathur M, Patil P, Bove A. The role of 3D printing in structural heart disease: all that glitters is not gold. JACC Cardiovasc Imaging. 2015; 8(8): 987-988, doi: 10.1016/j.jcmg.2015.03.009, indexed in Pubmed: 26271094.

32. Farooqi KM, Lengua CG, Weinberg AD, et al. Blood pool segmentation results in superior virtual cardiac models than myocardial segmentation for 3D printing. Pediatr Cardiol. 2016; 37(6): 1028-1036, doi: 10.1007/s00246-016-1385-8, indexed in Pubmed: 27041098

33. Gosnell J, Pietila T, Samuel BP, et al. Integration of computed tomography and three-dimensional echocardiography for hybrid three-dimensional printing in congenital heart disease. J Digit Imaging. 2016; 29(6): 665-669, doi: 10.1007/s10278-016-9879-8, indexed in Pubmed: 27072399.

34. Vukicevic M, Puperi D, Grande-Allen KJ, et al. 3D Printed Modeling of the Mitral Valve for Catheter-Based Structural Interventions. Ann Biomed Eng. 2016; 45(2): 508-519, doi: 10.1007/ s10439-016-1676-5.

35. Fujita B, Kütting M, Scholtz S, et al. Development of an algorithm to plan and simulate a new interventional procedure. Interact Cardiovasc Thorac Surg. 2015; 21(1): 87-95, doi: 10.1093/ icvts/ivv080, indexed in Pubmed: 25847966.

36. Rajani R, Khattar R, Chiribiri A, et al. Multimodality imaging of heart valve disease. Arq Bras Cardiol. 2014; 103(3): 251-263, indexed in Pubmed:24830387.

37. Schmauss D, Haeberle S, Hagl C, et al. Three-dimensional printing in cardiac surgery and interventional cardiology: a single-centre experience. Eur J Cardiothorac Surg. 2015; 47(6): 1044-1052, doi: 10.1093/ejcts/ezu310, indexed in Pubmed: 25161184.
38. Koleilat I, Jaeggli M, Ewing JA, et al. Interobserver variability in physician-modified endograft planning by comparison with a three-dimensional printed aortic model. J Vasc Surg. 2016; 64(6): 1789-1796, doi: 10.1016/j.jvs.2015.09.044, indexed in Pubmed: 26607872.

39. Garekar S, Bharati A, Chokhandre M, et al. Clinical application and multidisciplinary assessment of three dimensional printing in double outlet right ventricle with remote ventricular septal defect. World J Pediatr Congenit Heart Surg. 2016; 7(3): 344-350, doi: 10.1177/2150135116645604, indexed in Pubmed: 27142402.

40. Ripley B, Kelil T, Cheezum MK, et al. 3D printing based on cardiac CT assists anatomic visualization prior to transcatheter aortic valve replacement. J Cardiovasc Comput Tomogr. 2016; 10(1): 28-36, doi: 10.1016/j.jcct.2015.12.004, indexed in Pubmed: 26732862.

41. Mashari A, Knio Z, Jeganathan J, et al. Hemodynamic testing of patient-specific mitral valves using a pulse duplicator: a clinical application of three-dimensional printing. J Cardiothorac Vasc Anesth. 2016; 30(5): 1278-1285, doi: 10.1053/j.jvca.2016.01.013, indexed in Pubmed: 27179613.

42. Valverde I, Gomez G, Gonzalez A, et al. Three-dimensional patient-specific cardiac model for surgical planning in Nikaidoh procedure. Cardiol Young. 2015; 25(4): 698-704, doi: 10.1017/ S1047951114000742, indexed in Pubmed: 24809416.

43. Farooqi KM, Gonzalez-Lengua C, Shenoy R, et al. Use of a three dimensional printed cardiac model to assess suitability for biventricular repair. World J Pediatr Congenit Heart Surg. 2016; 7(3): 414-416, doi: 10.1177/2150135115610285, indexed in Pubmed: 27009890

44. Valverde I, Gomez G, Coserria JF, et al. 3D printed models for planning endovascular stenting in transverse aortic arch hypoplasia. Catheter Cardiovasc Interv. 2015; 85(6): 1006-1012, doi: 10.1002/ccd.25810, indexed in Pubmed: 25557983.

45. Sulaiman A, Boussel L, Taconnet F, et al. In vitro non-rigid life-size model of aortic arch aneurysm for endovascular prosthesis assessment. Eur J Cardiothorac Surg. 2008; 33(1): 53-57, doi: 10.1016/j.ejcts.2007.10.016, indexed in Pubmed: 18054246.

46. Mottl-Link S, Hübler M, Kühne T, et al. Physical models aiding in complex congenital heart surgery. Ann Thorac Surg. 2008; 86(1): 273-277, doi:10.1016/j.athoracsur.2007.06.001, indexed in Pubmed: 18573436.

47. Sodian R, Weber S, Markert M, et al. Stereolithographic models for surgical planning in congenital heart surgery. Ann Thorac Surg. 2007; 83(5): 1854-1857, doi: 10.1016/j.athoracsur.2006.12.004.

48. Chaowu Y, Hua Li, Xin S. Three-Dimensional printing as an aid in transcatheter closure of secundum atrial septal defect with rim deficiency: in vitro trial occlusion based on a personalized heart model. Circulation. 2016; 133(17): e608-e610, doi: 10.1161/CIRCULATIONAHA.115.020735, indexed in Pubmed: 27143157.

49. Yang F, Zheng H, Lyu J, et al. [A case of transcatheter closure of inferior vena cava type atrial septal defect with patent ductus arteriosus occlusion device guided by 3D printing technology]. Zhonghua Xin Xue Guan Bing Za Zhi, 2015. Zhonghua Xin Xue Guan Bing Za Zhi. 2015; 43(7): 631-633, indexed in Pubmed: 26420326.

50. Lazkani M, Bashir F, Brady K, et al. Postinfarct VSD management using 3D computer printing assisted percutaneous closure. Indian Heart J. 2015; 67(6): 581-585, doi: 10.1016/j. ihj.2015.09.021, indexed in Pubmed: 26702691. 
51. Otton J, Spina R, Sulas R, et al. Left atrial appendage closure guided by personalized 3d-printed cardiac reconstruction. JACC Cardiovasc Interv. 2015; 8(7): 1004-1006, doi: 10.1016/j. jcin.2015.03.015.

52. Liu K, Lyu B, Ren X, et al. [Prior transcatheter aortic valve implantation evaluation with 3D printing technology: a case report]. Zhonghua Xin Xue Guan Bing Za Zhi. 2015; 43(7): 634-635.

53. Schmauss D, Juchem G, Weber S, et al. Three-dimensional printing for perioperative planning of complex aortic arch surgery. Ann Thorac Surg. 2014; 97(6): 2160-2163, doi: 10.1016/j.athoracsur.2014.02.011, indexed in Pubmed: 24882292.

54. O'Neill B, Wang D, Pantelic M, et al. Transcatheter caval valve implantation using multimodality imaging: roles of TEE, CT, and 3D printing. JACC Cardiovascular Imaging. 2015; 8(2): 221-225, doi: 10.1016/j.jcmg.2014.12.006.

55. Poterucha JT, Foley TA, Taggart NW. Percutaneous pulmonary valve implantation in a native outflow tract: 3-dimensional DynaCT rotational angiographic reconstruction and 3-dimensional printed model. JACC Cardiovasc Interv. 2014; 7(10): e151-e152, doi: 10.1016/j.jcin.2014.03.015, indexed in Pubmed: 25341717.

56. Dankowski R, Baszko A, Sutherland M, et al. 3D heart model printing for preparation of percutaneous structural interventions: description of the technology and case report. Kardiol Pol. 2014; 72(6): 546-551, doi: 10.5603/KP.2014.0119.

57. Son KH, Kim KW, Ahn CB, et al. Surgical planning by 3D printing for primary cardiac schwannoma resection. Yonsei Med J. 2015; 56(6): 1735-1737, doi: 10.3349/ymj.2015.56.6.1735, indexed in Pubmed: 26446661.

58. Shirakawa T, Koyama Y, Mizoguchi H, et al. Morphological analysis and preoperative simulation of a double-chambered right ventricle using 3-dimensional printing technology. Interact Cardiovasc Thorac Surg. 2016; 22(5): 688-690, doi: 10.1093/icvts/ ivw009, indexed in Pubmed: 26860990.

59. Olivieri L, Krieger A, Chen MY, et al. 3D heart model guides complex stent angioplasty of pulmonary venous baffle obstruction in a Mustard repair of D-TGA. Int J Cardiol. 2014; 172(2): e297-e298, doi: 10.1016/j.ijcard.2013.12.192, indexed in Pubmed: 24447757.
60. Kiraly L, Tofeig M, Jha NK, et al. Three-dimensional printed prototypes refine the anatomy of post-modified Norwood- 1 complex aortic arch obstruction and allow presurgical simulation of the repair. Interact Cardiovasc Thorac Surg. 2016; 22(2): 238-240, doi: 10.1093/icvts/ivv320, indexed in Pubmed: 26590304.

61. Leotta DF, Starnes BW. Custom fenestration templates for endovascular repair of juxtarenal aortic aneurysms. J Vasc Surg. 2015; 61(6): 1637-1641, doi: 10.1016/j.jvs.2015.02.016, indexed in Pubmed: 25864045.

62. Hadeed K, Dulac Y, Acar P. Three-dimensional printing of a complex CHD to plan surgical repair. Cardiol Young. 2016; 26(7): 1432-1434, doi:10.1017/S1047951116000755, indexed in Pubmed: 27321706.

63. Jabbari OAl, Saleh WA, Patel A, et al. Use of three-dimensional models to assist in the resection of malignant cardiac tumors. J Cardiac Surg. 2016; 31(9): 581-583, doi: 10.1111/jocs.12812.

64. Hermsen JL, Burke TM, Seslar SP, et al. Scan, plan, print, practice, perform: Development and use of a patient-specific 3-dimensional printed model in adult cardiac surgery. J Thorac Cardiovasc Surg. 2017; 153(1): 132-140, doi: 10.1016/j. jtcvs.2016.08.007, indexed in Pubmed: 27650000.

65. Kim MS, Hansgen AR, Wink O, et al. Rapid prototyping: a new tool in understanding and treating structural heart disease. Circulation. 2008; 117(18): 2388-2394, doi: 10.1161/CIRCULATIONAHA.107.740977, indexed in Pubmed: 18458180.

66. Jacobs S, Grunert R, Mohr FW, et al. 3D-Imaging of cardiac structures using 3D heart models for planning in heart surgery: a preliminary study. Interact Cardiovasc Thorac Surg. 2008; 7(1): 6-9, doi: 10.1510/icvts.2007.156588, indexed in Pubmed: 17925319.

67. Farooqi KM, Saeed O, Zaidi A, et al. 3D printing to guide ventricular assist device placement in adults with congenital heart disease and heart failure. JACC Heart Fail. 2016; 4(4): 301-311, doi: 10.1016/j.jchf.2016.01.012, indexed in Pubmed: 27033018.

68. Bauch T, Vijayaraman P, Dandamudi G, et al. Three-Dimensional printing for in vivo visualization of his bundle pacing leads. Am J Cardiol. 2015; 116(3): 485-486, doi: 10.1016/j.amjcard.2015.04.061, indexed in Pubmed: 26071991. 